\title{
Visible-Light-Photocatalyzed Reductions of N-Heterocyclic Nitroaryls to Anilines Utilizing Ascorbic Acid Reductant
}

\section{Todorov, Aleksandar}

2019-05-17

Todorov , A , Aikonen, S A A , Muuronen, M \& Helaja , J 2019 , '

Visible-Light-Photocatalyzed Reductions of N-Heterocyclic Nitroaryls to Anilines Utilizing pÿAscorbic Acid Reductant ' , Organic Letters , vol. 21 , no. 10 , pp. 37643768 . https://doi.org/10.1021/acs.orglett.9

http://hdl.handle.net/10138/321993

https://doi.org/10.1021/acs.orglett.9b01205

cc_by

publishedVersion

Downloaded from Helda, University of Helsinki institutional repository.

This is an electronic reprint of the original article.

This reprint may differ from the original in pagination and typographic detail.

Please cite the original version. 


\title{
Visible-Light-Photocatalyzed Reductions of N-Heterocyclic Nitroaryls to Anilines Utilizing Ascorbic Acid Reductant
}

\author{
Aleksandar R. Todorov, Santeri Aikonen, ${ }^{\circledR}$ Mikko Muuronen, ${ }^{\dagger}{ }^{\dagger}$ and Juho Helaja*(i) \\ Department of Chemistry, University of Helsinki, A.I. Virtasen aukio 1, 00014 Helsinki, Finland \\ Supporting Information
}

ABSTRACT: A photoreductive protocol utilizing [Ru(bpy) $\left.]_{3}\right]^{2+}$ photocatalyst, blue light LEDs, and ascorbic acid $\left(\mathrm{AscH}_{2}\right)$ has been developed to reduce nitro N-heteroaryls to the corresponding anilines. Based on experimental and computational results and previous studies, we propose that the reaction proceeds via proton-coupled electron transfer between $\mathrm{AscH}_{2}$, photocatalyst, and the nitro N-heteroaryl.

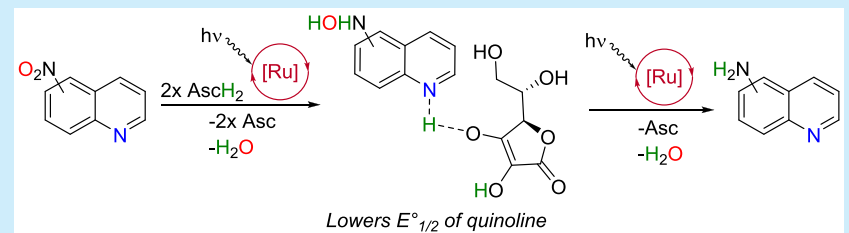
The method offers a green catalytic procedure to reduce, e.g., 4-/8-nitroquinolines to the corresponding aminoquinolines, substructures present in important antimalarial drugs.

$\mathrm{R}$ eduction of an aromatic nitro compound is a prototypical way to prepare arylamines that are common substructures in pharmaceuticals, agrochemicals, dyes, and pigments and in a variety of other fine and specialty chemicals. ${ }^{1}$ This fundamental transformation can be performed using a plethora of synthetic and catalytic protocols: conventional stoichiometric reagents, e.g., $\mathrm{SnCl}_{2}, \mathrm{TiCl}_{3}$, Raney $\mathrm{Ni}, \mathrm{Zn}, \mathrm{Sn}, \mathrm{Fe}$, and $\mathrm{Na}_{2} \mathrm{~S}$, are appropriate for specific lab-scale conversion, ${ }^{2}$ while transitionmetal-catalyzed hydrogenations (e.g., $\mathrm{Pd}, \mathrm{Au}$, and $\mathrm{Pt}$ on various supports: $\mathrm{C}, \mathrm{TiO}_{2}$, etc.) dominate industrial applications. ${ }^{3}$ Lately, heterogeneous photocatalytic nitroarene reductions on various materials, e.g., semiconductors, nanoparticles, and nanocomposites, have also been under intensive development. ${ }^{4}$

Recent advances in photoredox catalysis (e.g., metal complexes and organic dyes) have enabled new strategies for reductive organic conversions. ${ }^{5}$ The early photoreductions of nitrobenzenes to anilines were carried out under intense xenon lamp irradiation including UV wavelengths. In a pioneering example, Fukuzumi and co-workers used an excess of dihydroacridine as a reductant for triplet excited $\mathrm{PhNO}_{2}$ in the presence of $\mathrm{HClO}_{4} / \mathrm{H}_{2} \mathrm{O}$ additives in $\mathrm{MeCN} .^{6}$ Later on, Hirao and co-workers developed a more convenient method, exploiting a $\mathrm{Ru}(\mathrm{bpy})_{2}(\mathrm{MeCN})_{2}\left(\mathrm{PF}_{6}\right)_{2}$ photosensitizer and hydrazine as reductant, while the most intense UV light was filtered out $(<300 \mathrm{~nm}){ }^{7}$ Ananthakrishnan and co-workers employed visible light in 4-nitrophenol photoreduction using resin-supported eosin $\mathrm{Y}$ with a large excess of $\mathrm{NaBH}_{4}$ (Scheme 1a). ${ }^{8}$ Tung and co-workers developed the method further to extend the substrate scope by utilizing green light-emitting diodes (LEDs) as a light source, eosin $\mathrm{Y}$ as a photosensitizer, and triethanolamine (TEOA) as a reductant (Scheme 1b). ${ }^{9}$

Our interest has been in the development of catalytic methods for quinoline modifications. Previously, we developed a protocol for photoreductive removal of $O$-benzyl groups from oxyarene N-heterocycles. ${ }^{10}$ At the beginning of the current study, we observed that even the eosin Y/TEOA photoreduction protocol (Scheme $1 \mathrm{~b}$ ) was widely tolerant for
Scheme 1. Visible Light Nitroaryl Photoreduction Reduction Protocols

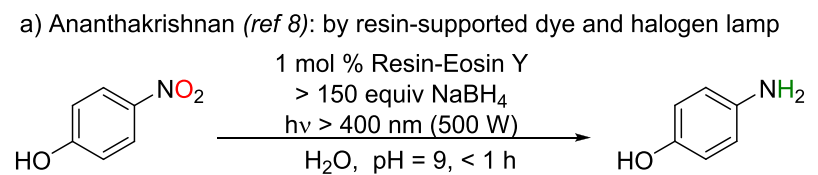

b) Tung (ref 9): green protocol for nitroaryl reductions

$93 \%$ yield

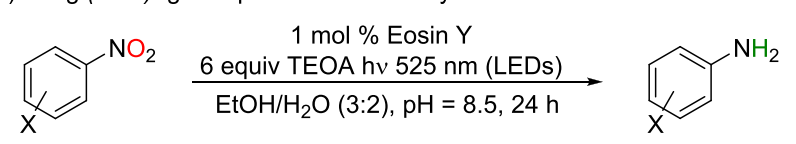

$\mathrm{X}: \mathrm{H}, \mathrm{Cl}, \mathrm{Br}, \mathrm{COCH}_{3}, \mathrm{CHO}, \mathrm{C} \equiv \mathrm{CH}$

$90-99 \%$ yields $\mathrm{CH}_{3}, \mathrm{CN}$, OMe,

c) This work: Selective visible-light protocol for nitro-N-heteroaryls<smiles>[X]c1cc2cccnc2cc1[N+](=O)[O-]</smiles>
\begin{tabular}{c}
$1 \mathrm{~mol} \% \mathrm{Ru}(\mathrm{bpy})_{3} \mathrm{Cl}_{2}{ }^{*} 6 \mathrm{H}_{2} \mathrm{O}$ \\
4 equiv of AscH ${ }_{2}$ \\
\hline $\mathrm{h} v 455 \mathrm{~nm}$ (LEDs) \\
$\mathrm{MeOH} / \mathrm{H}_{2} \mathrm{O}(4: 1)$ Argon, rt 1-5 h
\end{tabular}<smiles>[X]c1cc2cccnc2cc1N</smiles>

$\mathrm{X}: \mathrm{H}, \mathrm{Br}$, OMe, O-allyl, O-Bn, $\mathrm{OCOCH}_{3}, \mathrm{OTf}, \mathrm{C} \equiv \mathrm{C}_{4} \mathrm{H}_{9}$

upto $98 \%$ yields

nitrophenyl functional groups, the method was incompatible with nitroquinolines (Table S7). Therefore, we developed here a photocatalytic protocol for reducing nitro groups in $\mathrm{N}$ (oxo)heterocyclic nitroaryls (Scheme 1c) leading to aminoquinoline structures present in many important antimalarial pharmaceuticals, e.g., in traditional chloroquine ${ }^{11}$ and primaquine $^{12}$ as well as recently FDA-approved tafenoquine ${ }^{13}$ (Figure 1).

First, we studied the photoreduction of 2-methoxy-6nitroquinoline 1a in the presence of ascorbic acid $\left(\mathrm{AscH}_{2}\right)$

Received: April 5, 2019

Published: May 8, 2019 


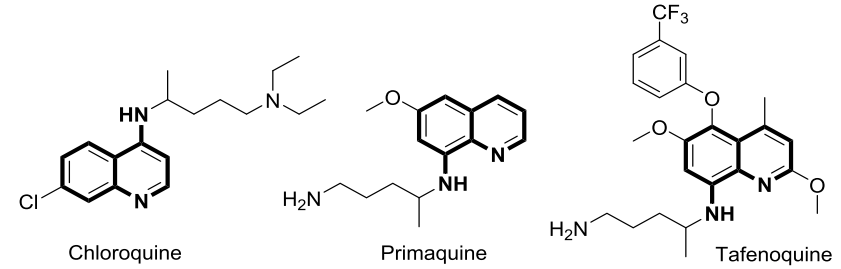

Figure 1. Examples of 4-/8-aminoquinoline-containing antimalarial drugs.

Table 1. Effect of Deviation from Standard Reaction Conditions $^{a}$

variation from standard conditions
Argon, rt, $1 \mathrm{~h}$

${ }^{a}$ Full reaction optimization in Tables $\mathrm{S} 1-\mathrm{S} 7 .{ }^{b} \mathrm{GC}$ yield: average of two runs. ${ }^{c}$ Isolated yield by $\mathrm{SiO}_{2}$ column chromatography

as the reductant and $\mathrm{Ru}(\mathrm{bpy})_{3} \mathrm{Cl}_{2}$ as the photosensitizer according to earlier successful protocols for reductions by us and others. ${ }^{14}$ Optimization of the reaction conditions, i.e., photocatalyst, reductant amount, solvent, concentration, and reaction time, provided aniline 2 a with $83 \%$ yield after $1 \mathrm{~h}$ irradiation with blue LEDs light $(455 \mathrm{~nm})$ in the presence of 4 equiv of $\mathrm{AscH}_{2}$ and $1 \mathrm{~mol} \%$ of the [Ru] catalyst in $\mathrm{MeOH} /$ $\mathrm{H}_{2} \mathrm{O}(0.02 \mathrm{M})$ at $\mathrm{rt}$ (Tables $\left.\mathrm{S} 1-\mathrm{S} 7\right)$. Varying the reaction conditions from the optimal shows that reaction does not take place without light, $\mathrm{AscH}_{2}$, or photocatalyst and the reaction is sensitive to air atmosphere (entries $2,8,4$, and 3 Table 1 ). The reaction was also sensitive to the amount of reactants (entries 5, 9, and 10), and interestingly, the optimal solvent compositions proved to be $4: 1 \mathrm{MeOH} / \mathrm{H}_{2} \mathrm{O}$ and $1: 1 \mathrm{EtOH} /$ $\mathrm{H}_{2} \mathrm{O}$. The reaction proceeds poorly or not at all in polar aprotic solvents, e.g., $\mathrm{DMF}$ and $\mathrm{MeCN}$, even though $\mathrm{MeCN}$ was employed as solvent in the previous $\mathrm{AscH}_{2}$ and $[\mathrm{Ru}]$ photocatalyst studies. $^{14}$

Next, we studied the scope of the reaction (Scheme 2); reduction of nitromethoxyquinolines $\mathbf{1 b}-\mathbf{1 f}$ to the correspond-
Scheme 2. Reaction Scope Study ${ }^{a}$

\begin{tabular}{|c|c|c|}
\hline \multirow{2}{*}{$\begin{array}{l}\mathrm{NO}_{2}-\mathrm{N} \text {-heteroaryl } \\
\mathbf{1 b} \text {-1k }\end{array}$} & $\begin{array}{c}\text { Ascorbic acid } 4 \text { equiv } \\
\mathrm{Ru}(\mathrm{bpy})_{3} \mathrm{Cl}_{2}{ }^{*} 6 \mathrm{H}_{2} \mathrm{O} 1 \mathrm{~mol} \% \\
\end{array}$ & \\
\hline & $\begin{array}{l}455 \mathrm{~nm} \text { LEDs } \\
\mathrm{MeOH}: \mathrm{H}_{2} \mathrm{O}(4: 1)[0.02 \mathrm{M}] \\
\text { Argon, rt, time }\end{array}$ & $2 b-2 k$ \\
\hline
\end{tabular}<smiles>COc1ccnc2ccc(N)cc12</smiles>

2b: 1.5 h, $97 \%$<smiles>COc1cc(N)c2ncccc2c1</smiles>

2e: 5 h, $86 \%$

$(20 \mathrm{~h}, 73 \%)^{\mathrm{b}}$<smiles>Nc1ccc2cccnc2c1</smiles>

2h: 4.5 h, $99 \%$<smiles>Cc1ccc2cccc(N)c2n1</smiles>

2k: 3.5 h, $90 \%$<smiles>CC(=O)Oc1cc(N)c2nc(C)ccc2c1</smiles>

2n: 3 h, $91 \%$<smiles>COc1ccnc2c(N)cccc12</smiles>

2c: 2 h, $90 \%$<smiles>COc1ccnc2c(N)cc(Br)cc12</smiles>

2f: $2.5 \mathrm{~h}, 98 \%$<smiles>Nc1ccc2ncccc2c1</smiles>

2i: 3 h, $69 \%$<smiles>CCCOc1ccc(N)c2cccnc12</smiles>

2I: $6 h, 16 \%$<smiles>Cc1ccc2cc(O)cc(N)c2n1</smiles>

2o: 7.5 h, $96 \%$<smiles>COc1ccc2cccc(N)c2n1</smiles>

2d: 3.5 h, $40 \%$<smiles>Nc1cccc2cccnc12</smiles>

2g: $4 h, 75 \%$<smiles>Nc1cccc2ncccc12</smiles>

2j: 3.5 h, $76 \%$<smiles>C=CCOc1cc(N)c2nc(C)ccc2c1</smiles>

2m: 4 h, $83 \%$<smiles>CCCCCCC#Cc1cc(N)c2nccc(OC)c2c1</smiles>

2p: 23 h, 79\%
From $\mathrm{N}$-oxo quinolines<smiles>Nc1ccnc2ccccc12</smiles>

2q: 3 h, $57 \%$<smiles>Nc1cccc2ncccc12</smiles>

2j: 5 h, 35\%<smiles>Nc1ccc2ncccc2c1</smiles>

2i: 5 h, $25 \%$
Other $\mathrm{N}$-heterocycles<smiles>Nc1cccc2cnccc12</smiles>

2r: 5 h, 34\%

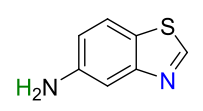

2s: 2 h, $53 \%$
${ }^{a}$ Average isolated yields of two runs after $\mathrm{SiO}_{2}$ chromatography. ${ }^{b} \mathrm{Up}$ scaled $(4 \mathrm{mmol})$ reaction under the same light source, $0.5 \mathrm{~mol} \%$ of $[\mathrm{Ru}]$ catalyst.

ing amines $\mathbf{2} \mathbf{b}-\mathbf{2} \mathbf{f}$ required slightly longer reactions times, $1.5-5 \mathrm{~h}$, depending on the substituent positions. The obtained yields were, however, still high (86-97\%) with $2 \mathrm{~d}$ being an exception by producing unidentified polymeric side products. 
Scheme 3. Synthesis of Hydroxylamine and Nitrone<smiles>CC(=O)n1ncc2c(N)c(O)ccc21</smiles>

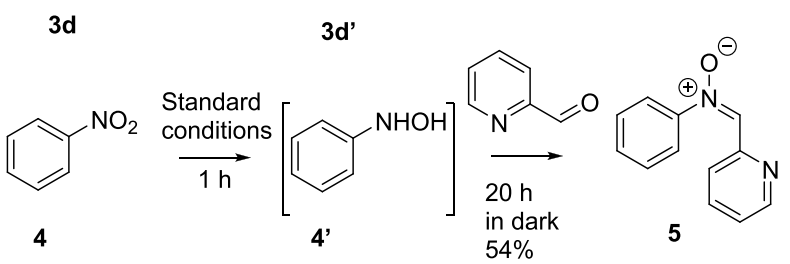

The excellent yield of $\mathbf{2 f}$ demonstrates that halogen substituents in the nitro/amino aryl ring are also well tolerated. In addition, the monosubstituted 5-, 6-, 7-, or 8-nitroquinolines are converted into amines $\mathbf{2 g}-\mathbf{2 j}$ with up to quantitative yields, and the 2-methyl substituent improved the 8-aminoquinoline yield from 75 to $90 \%$ ( $\mathbf{2 g}$ vs $\mathbf{2 k}$ ). Importantly, the protocol proved to be scalable: reduction of 1 e on a larger $4 \mathrm{mmol}$ (vs $0.2 \mathrm{mmol})$ scale with reduced catalyst loading ([Ru $0.5 \mathrm{~mol}$ $\%$ ) yielded $73 \%$ of $2 \mathrm{e}$ after $24 \mathrm{~h}$ reaction time.

A poor yield of $16 \%$ received for 21 indicates that the combination of 6-nitro-8-ether substitution is unfavorable for the reaction. On the other hand, 2-methyl-8-nitroquinolines with allyl ether, acyl, or triflyl at the 6-position gave high yields of $83 \%, 91 \%$, and $96 \%$ for $\mathbf{2 m}, \mathbf{2 n}$, and $\mathbf{2 0}$, respectively, although the TfO compound (2o) required longer reaction time $(7.5 \mathrm{~h})$. The chemoselectivity of the method was further

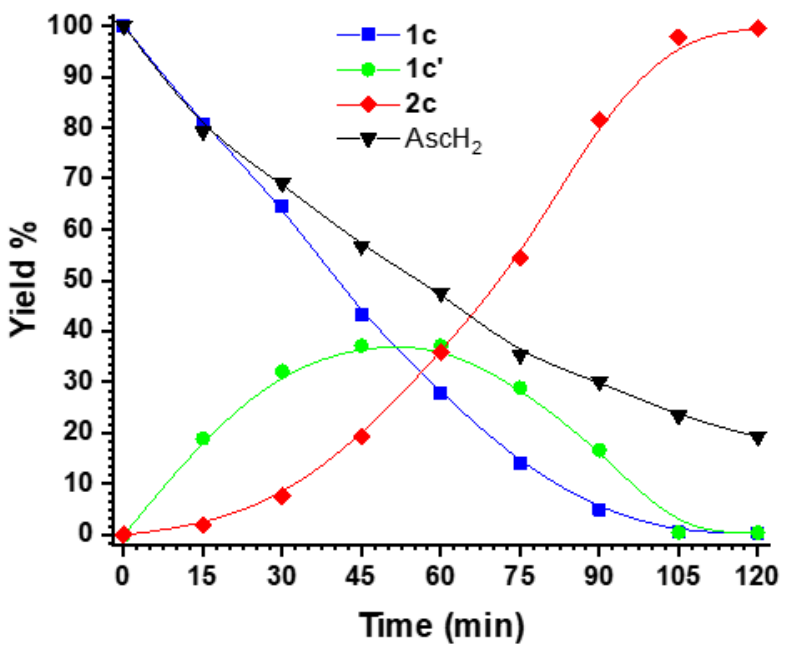

Figure 3. Conversion of $1 \mathrm{c}$ to $2 \mathrm{c}$ via observed hydroxylamine intermediate $\mathbf{1} \mathbf{c}^{\prime}$ followed by ${ }^{1} \mathrm{H}$ NMR monitoring (SI). Structures are presented in Figure 2a.

highlighted with a $79 \%$ yield of 6-alkyne-substituted 8-amino4-methoxyquinone $2 \mathrm{p}$ after $23 \mathrm{~h}$ reaction time.

Another attractive class of target molecules is 4-nitroquinolines (Scheme 2), which are commonly prepared by nitration of $\mathrm{N}$-oxoquinolines and require the use of trivalent phosphorus compounds for removal of the $\mathrm{N}$-oxo groups. ${ }^{15}$ Our received yields of $57 \%, 35 \%$, and $25 \%$ for $\mathbf{2 q}, \mathbf{2 i}$, and $2 \mathbf{j}$, respectively, using $\mathrm{N}$-oxo compounds as starting materials are therefore highly encouraging.

a) Proton transfer (PT)

a) Single-electron transfer (SET)

Concerted or step-wise

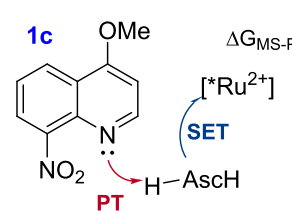

A

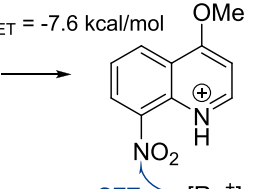
SET $\left[\mathrm{Ru}^{+}\right]$ $\Delta \mathrm{G}_{\mathrm{SET}}=-25.1 \mathrm{kcal} / \mathrm{mol}$

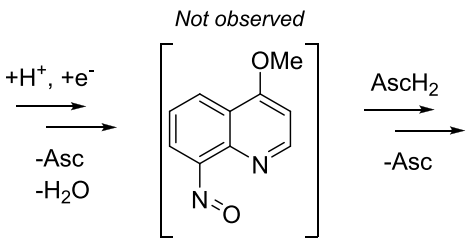

Accumulates during reaction HRMS $(\mathrm{m} / \mathrm{z}=191.0814[\mathrm{M}+\mathrm{H}])$<smiles>COc1cc[n+](CC([In])C(C)(C)C)c2c(NO)cccc12</smiles>

$\Delta \mathrm{G}_{\mathrm{PT}}=-0.8 \mathrm{kcal} / \mathrm{mol}$

c
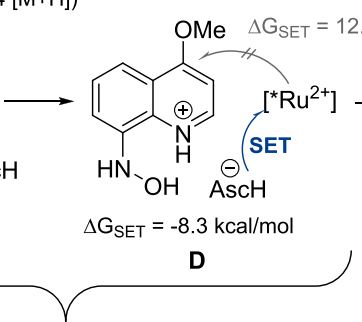

(S)

.

Concerted or step-wise

$\Delta \mathrm{G}_{\mathrm{MS}-\mathrm{PCET}}=-9.1 \mathrm{kcal} / \mathrm{mol}$

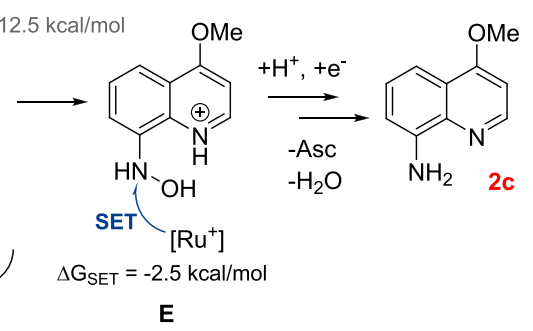

b) Condensation intermediates, not observed

Figure 2. (a) Schematic representation of the nitro reduction to amine. (b) Condensation intermediates. 


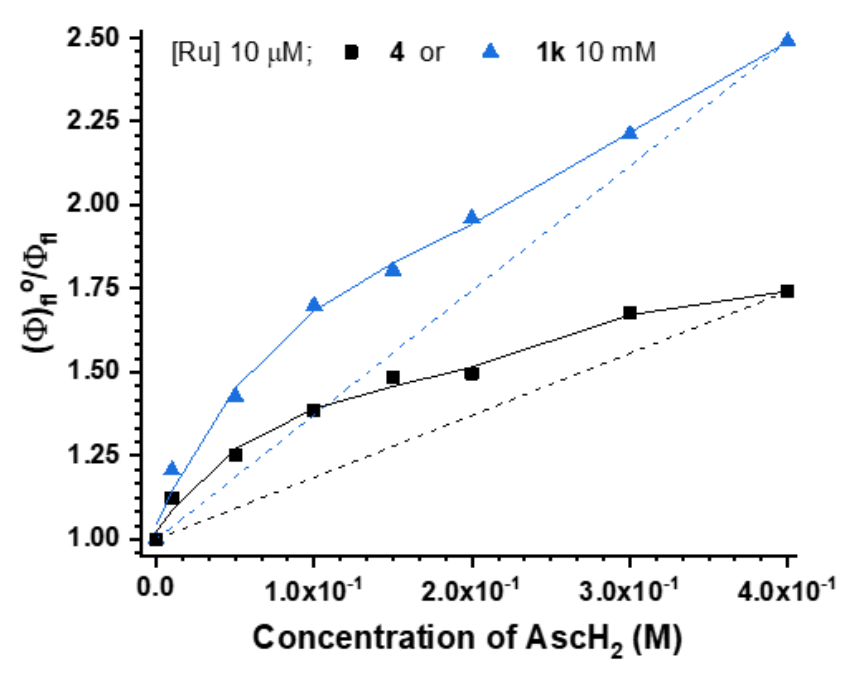

Figure 4. Modified Stern-Volmer titration, where $[\mathrm{Ru}]$ and quencher 1k or 4 were kept constant and $\mathrm{AscH}_{2}$ quencher was varied.

Last, we also tested the substrate scope for producing 6aminoisoquinoline $2 \mathrm{r}$ and 5-aminobenzothiazole 2s, which worked with decent to good yields (Scheme 2). Other tested $\mathrm{N}$-heterocycles fell into the category of unsuitable substrates $(\mathbf{3} \mathbf{a}-\mathbf{3 h}, \mathrm{SI})$, being either unreactive, stopping at hydroxylamine intermediate stage (3d, Scheme 3 ), or leading to side products and oligomerization, which limit the scope of the method.

Interestingly, for 1-acyl-4-nitroindazole $\mathbf{3 d}$ and nitrobenzene 4 ,very good yields (79\%) of hydroxylamine $3 \mathbf{d}^{\prime}$ and (54\%) nitrone 5, respectively, were obtained instead of their amine products (Scheme 3). Therefore, we decided to study the reaction mechanism to understand why the reaction is not driven to amine formation in these cases.

First, the mechanism of the photoreduction was studied by monitoring the conversion of $\mathbf{1} \mathbf{c}$ to $2 \mathrm{c}$ with NMR. Hydroxylamine intermediate $\left(\mathbf{1} \mathbf{c}^{\prime}\right)$ was increasingly formed and consumed in the course of the reaction (Figures $2 \mathrm{a}$ and 3 and SI) in accordance with the previously proposed mechanism for the nitrobenzene reduction. ${ }^{16,17}$ The acquired NMR data showed no traces of other species, indicating that the reduction proceeds via the direct route (Figure $2 \mathrm{a}$ and SI) rather than through the condensation of hydroxylamine and nitroso intermediates (Figure $2 \mathrm{~b}$ ).

Initially, we considered the first step of the mechanism to be reduction of substrate, or protonation of the substrate followed by its reduction. However, Stern-Volmer measurements pointed out that a $1: 1$ mixture of $1 \mathrm{k} / \mathrm{AscH}_{2}$ was a superior quencher of $\left[* \mathrm{Ru}^{2+}\right]$ compared to either of the components alone, indicating their cooperative role (SI). Furthermore, the computed oxidation potentials indicate oxidation of ascorbic acid with $\left[{ }^{*} \mathrm{Ru}^{2+}\right]$ to be an endergonic process $(17.5 \mathrm{kcal} / \mathrm{mol}$, SI), and neither do the experimentally observed yields correlate with the computed reduction potentials of the protonated or nonprotonated substrates (see SI for $E_{\text {red }}^{\circ}$ and $E_{\text {red,H+ }}^{\circ}$ values). Therefore, we propose the mechanism depicted in Figure 2a: (A) the reaction is initiated by a multisite proton-coupled electron transfer (MS-PCET) ${ }^{18}$ between the nitro quinoline, $\mathrm{AscH}_{2}$, and $\left[* \mathrm{Ru}^{2+}\right]$, i.e., proton and electron are transferred from one donor to two separate acceptors. This is supported by Stern-Volmer titrations for $\mathbf{1 k}$ and nitrobenzene (4), in which concentrations of these substrates were fixed and the amount of $\mathrm{AscH}_{2}$ was varied (Figure 4). The nonlinear behavior in both cases indicates an MS-PCET-type reaction as suggested by Qiu and Knowles. ${ }^{18 \mathrm{~b}}$ Next, (B) the protonated nitro substrate is reduced by $\left[\mathrm{Ru}^{+}\right]$: reduction of protonated nitro compound with $\left[\mathrm{Ru}^{+}\right]$is a more exergonic process $(\Delta G \leq-15.9 \mathrm{kcal} / \mathrm{mol})$ than with $\left[* \mathrm{Ru}^{2+}\right]$ $(-12.7[\mathbf{1 g}] \leq \Delta G \leq-0.9[3 \mathrm{~d}] \mathrm{kcal} / \mathrm{mol})$, and reduction of $\left[* \mathrm{Ru}^{2+}\right]$ to $\left[\mathrm{Ru}^{+}\right]$by $\mathrm{AscH}^{-}$is an exergonic process $(-8.3$ $\mathrm{kcal} / \mathrm{mol})$. The protonation energies of reactive nitro substrates by $\mathrm{AscH}_{2}$ were calculated to vary between thermoneutral $(0.7 \mathrm{kcal} / \mathrm{mol}$ for $1 \mathrm{c})$ and endergonic (15.4 $\mathrm{kcal} / \mathrm{mol}$ for $3 \mathrm{~d}$ ), where the endergonicity of protonation does not exclude hydrogen-bonding interactions between acid and base, which in turn can facilitate MS-PCET reactions. ${ }^{18}$

The protonation of hydroxylamine (C) and the subsequent reduction of $\left[* \mathrm{Ru}^{2+}\right]$ to $\left[\mathrm{Ru}^{+}\right]$by $\mathrm{AscH}^{-}(\mathrm{D})$ are required for the reduction of the substrate by $\left[\mathrm{Ru}^{+}\right](\mathrm{E}$, Figure $2 \mathrm{a})$, as the reduction of electron-rich hydroxylamine quinolines would be endergonic with $* \mathrm{Ru}(\mathrm{bpy}){ }_{3}{ }^{2+}(\Delta G \geq 27.9 \mathrm{kcal} / \mathrm{mol}, \mathrm{SI})$. The $\mathrm{pK}_{\mathrm{aH}}$ values for unreactive hydroxylamine intermediates of $3 \mathrm{~d}$ and 4 indicates that the protonation is endergonic: $10.1 \mathrm{kcal} /$ $\mathrm{mol}$ for $3 \mathbf{d}^{\prime}$ and $8.9 \mathrm{kcal} / \mathrm{mol}$ for $\mathbf{4}^{\prime}$. In turn, the reactive hydroxylamine intermediates are easily protonated (C, Figure $2 \mathrm{a})$ with free energies of $-0.8,2.4$, and $2.0 \mathrm{kcal} / \mathrm{mol}$ for $1 \mathrm{c}, 1 \mathrm{~d}$, and $1 \mathrm{~g}$, respectively. The reduction of protonated hydroxylamine quinolines would be endergonic with $\left[* \mathrm{Ru}^{2+}\right](4.8 \leq$ $\Delta G \leq 12.5 \mathrm{kcal} / \mathrm{mol}, \mathrm{SI})$, while the process is exergonic with the obtained ground state $\left[\mathrm{Ru}^{+}\right](\Delta G \leq-2.5 \mathrm{kcal} / \mathrm{mol}, \mathrm{SI})$.

In summary, we have developed a chemoselective and green photoreductive protocol for reduction of nitro N-heteroaryls that exploits $\mathrm{AscH}_{2}$ as hydrogen source. The method complements the existing photoredox catalysis protocols, extending their applicability for the $\mathrm{N}$-heteroaryls.

\section{ASSOCIATED CONTENT}

\section{Supporting Information}

The Supporting Information is available free of charge on the ACS Publications website at DOI: 10.1021/acs.orglett.9b01205.

Experimental procedures, full reaction optimization tables, ${ }^{1} \mathrm{H}$ NMR reaction monitoring, computational procedures and details, and ${ }^{1} \mathrm{H}$ and ${ }^{13} \mathrm{C}$ NMR spectra for all compounds (PDF)

\section{AUTHOR INFORMATION}

\section{Corresponding Author}

*E-mail: juho.helaja@helsinki.fi. ORCID

Santeri Aikonen: 0000-0003-2675-7290

Mikko Muuronen: 0000-0001-9647-7070

Juho Helaja: 0000-0001-8645-617X

\section{Present Address}

$\dagger$ (M.M.) BASF SE, Carl-Bosch-Str. 38, 67056 Ludwigshafen, Germany.

\section{Notes}

The authors declare no competing financial interest. 


\section{ACKNOWLEDGMENTS}

Financial support from the Academy of Finland (Project No. 129062) is acknowledged. The Finnish National Centre for Scientific Computing (CSC) is recognized for computational resources.

\section{REFERENCES}

(1) Selected reviews: (a) Handbook of reagents for organic synthesis, oxidising and reducing agents; Burk, S. D., Danheiser, R. L., Eds.; Wiley-VCH: New York, 1999. (b) Nitro compounds, aromatic. In Ullmann's Encyclopedia of Industrial Chemistry; Booth, G., Ed.; WileyVCH: Weinheim, 2012.

(2) Selected reviews: (a) Hydrogenation methods; Rylander, P. N., Ed.; Academic Press: New York, 1985. (b) Comprehensive organic synthesis. Selectivity, strategy and efficiency in modern organic chemistry; Trost, B. M., Fleming, I., Eds.; Pergamon: Oxford, 1991.

(3) Orlandi, M.; Brenna, D.; Harms, R.; Jost, S.; Benaglia, M. Recent developments in the reduction of aromatic and aliphatic nitro compounds to amines. Org. Process Res. Dev. 2018, 22, 430-445.

(4) Selected reviews: (a) Valenzuela, M. A.; Albiter, E.; Ríos-Bernÿ, O.; Córdova, I.; Flores, S. O. Photocatalytic Reduction of Organic Compounds. J. Adv. Oxid. Technol. 2010, 13, 321-340. (b) Kadam, H. K.; Tilve, S. G. Advancement in methodologies for reduction of nitroarenes. RSC Adv. 2015, 5, 83391-83407.

(5) Organic photoredox catalysis reviews: (a) Prier, C. K.; Rankic, D. A.; MacMillan, D. W. C. Visible light photoredox catalysis with transition metal complexes: applications in organic synthesis. Chem. Rev. 2013, 113, 5322-5363. (b) Shaw, M. H.; Twilton, J.; MacMillan, D. W. C. Photoredox catalysis in organic chemistry. J. Org. Chem. 2016, 81, 6898-6926. (c) Romero, N. A.; Nicewicz, D. A. Organic photoredox catalysis. Chem. Rev. 2016, 116, 10075-10166.

(6) Fukuzumi, S.; Tokuda, Y. Efficient six-electron photoreduction of nitrobenzene derivatives by 10-Methyl-9,10-dihydroacridine in the presence of perchloric acid. Bull. Chem. Soc. Jpn. 1992, 65, 831-836.

(7) Hirao, T.; Shiori, J.; Okahata, N. Ruthenium-bipyridine complex catalyzed photo-induced reduction of nitrobenzenes with hydrazine. Bull. Chem. Soc. Jpn. 2004, 77, 1763-1764.

(8) Gazi, S.; Ananthakrishnan, R. Metal-free-photocatalytic reduction of 4-nitrophenol by resin-supported dye under the visible irradiation. Appl. Catal., B 2011, 105, 317-325.

(9) Yang, X.-J.; Chen, B.; Zheng, L.-Q.; Wu, L.-Z.; Tung, C.-H. Highly efficient and selective photocatalytic hydrogenation of functionalized nitrobenzenes. Green Chem. 2014, 16, 1082-1086.

(10) Todorov, A. R.; Wirtanen, T.; Helaja, J. Photoreductive removal of $O$-benzyl groups from oxyarene $N$-heterocycles assisted by O-pyridine-pyridone tautomerism. J. Org. Chem. 2017, 82, 1375613767.

(11) Vale, N.; Moreira, R.; Gomes, P. Primaquine revisited six decades after its discovery. Eur. J. Med. Chem. 2009, 44, 937-953.

(12) Loria, P.; Miller, S.; Foley, M.; Tilley, L. Inhibition of the peroxidative degradation of haem as the basis of action of chloroquine and other quinoline antimalarials. Biochem. J. 1999, 339, 363-370.

(13) Berman, J.; Brown, T.; Dow, G.; Toovey, S. Tafenoquine and primaquine do not exhibit clinical neurologic signs associated with central nervous system lesions in the same manner as earlier 8aminoquinolines. Malar. J. 2018, 17, 1-12.

(14) (a) Edson, J. B.; Spencer, L. P.; Boncella, J. M. Photorelease of primary aliphatic and aromatic amines by visible-light-induced electron transfer. Org. Lett. 2011, 13, 6156-6159. (b) Binstead, R. A.; McGuire, M. E.; Dovletoglou, A.; Seok, W. K.; Roecker, L. E.; Meyer, T. J. Oxidation of hydroquinones by $\left[(\mathrm{bpy})_{2}(\mathrm{py}) \mathrm{Ru}^{\mathrm{IV}}(0)\right]^{2+}$ and $\left[(\mathrm{bpy})_{2}(\mathrm{py}) \mathrm{Ru}^{\mathrm{III}}(\mathrm{OH})\right]^{2+}$. Proton-coupled electron transfer. $J$. Am. Chem. Soc. 1992, 114, 173-186.

(15) (a) Brown, E. V. Preparation and Reactions of 2-Nitropyridinel-oxides. J. Am. Chem. Soc. 1957, 79, 3565-3566. (b) Emerson, T. R.; Rees, C. W. The deoxygenation of heterocyclic N-oxides. Part III. Kinetics of their reactions with phosphorus trichloride in chloroform. J. Chem. Soc. 1964, 0, 2319-2325. (c) Ross, W. C. The preparation of some 4-substituted nicotinic acids and nicotinamides. J. Chem. Soc. C 1966, 0, 1816-1821.

(16) Gelder, E. A.; Jackson, S. D.; Lok, C. M. The hydrogenation of nitrobenzene to aniline: a new mechanism. Chem. Commun. 2005, $522-524$.

(17) Haber, F. Über stufenweise reduktion des nitrobenzol mit begrenztem kathodpotential. Z. Elektrochem. Angew. Phys. Chem. 1898, 4, 506-514.

(18) (a) Biczók, L.; Gupta, N.; Linschitz, H. Coupled electronproton transfer in interactions of triplet $\mathrm{C}_{60}$ with hydrogen-bonded phenols: Effects of solvation, deuteration, and redox potentials. J. Am. Chem. Soc. 1997, 119, 12601-12609. (b) Qiu, G.; Knowles, R. R. Rate-driving force relationship in multisite proton-coupled electron transfer activation of ketones. J. Am. Chem. Soc. 2019, 141, 27212730. 